\section{Increasing Chilling Reduces Heat Requirement for Floral Budbreak in Peach}

\author{
William R. Okie ${ }^{1}$ and Bryan Blackburn \\ USDA, Agricultural Research Service, Southeastern Fruit and Tree Nut \\ Research Laboratory, 21 Dunbar Road, Byron, GA 31008
}

Additional index words. Prunus persica, dormancy, chilling

Abstract. Response to chilling temperatures is a critical factor in the suitability of peach [Prunus persica (L.) Batsch] cultivars to moderate climates such as in the southeastern United States. Time of bloom depends on the innate chilling requirement of the cultivar as well as the timing and duration of cold and warm temperatures experienced by the buds. Most current chilling models have considered dormancy break a sequential process: after appropriate chilling is received, a fixed amount of heat accumulation will produce bloom. This research shows that as chilling exposure increases, the time and heat accumulation required for peach floral budbreak decreases in an exponential relationship. When chilling is ample, a sequential, two-part dormancy model is adequate to describe budbreak, and increased chilling has little effect on heat requirement. In lower-chilling situations relative to a particular cultivar, the curvilinear relationship between chilling and heat requirement results in more heat being required for budbreak. This relationship, in conjunction with the range of chilling requirement found among the buds on a tree, results in an extended, asymmetrical budbreak.
Winter chilling in the southeastern United States and similar climates varies by location as well as from year to year. For successful peach production, cultivars must be chosen to match the chilling regime for a particular location such that adequate chilling is received for normal development but bloom is late enough to avoid frosts. Trees suffering from insufficient chilling break leaf and flower buds slowly and erratically, if at all (Chandler et al., 1937; Weinberger, 1950b). The starting date and duration of bloom for a given cultivar will vary depending on the timing and amount of chilling received. For many years, scientists have sought a clearer understanding of the effects of temperature on dormant bud development (Dennis, 2003). The major horticultural chilling models include the Weinberger "hours of chilling" (Weinberger, 1950a), the Utah weighted "chill units" (Anderson et al., 1986; Richardson et al., 1974), and the Dynamic Model "chilling portions" (Erez et al., 1990; Fishman et al., 1987). Although each of these models represented an advance in understanding the process, a robust model that can predict bloom across a wide range of environments is still lacking.

Chandler et al. (1937) summarized the relative need for chilling temperatures by fruit

Received for publication 31 Aug. 2010. Accepted for publication 12 Nov. 2010.

Mention of trade names or commercial products in this publication is solely for the purpose of providing specific information and does not imply recommendation or endorsement by the U.S. Department of Agriculture. The USDA is an equal opportunity provider and employer.

${ }^{1}$ To whom reprint requests should be addressed; e-mailwilliam.okie@ars.usda.gov. crops. Weinberger (1950a) developed a comparative scale to rate the effects of cold temperatures on buds of peach cultivars based on ideas formulated by L. Hutchins (pathologist with USDA, Fort Valley, GA). Higher numbers of hours $7.2^{\circ} \mathrm{C}$ or less (originally reported as $45^{\circ} \mathrm{F}$ ) correlated with normal budbreak and fruit set in Georgia. In years with fewer hours by 15 Feb., certain cultivars bloomed erratically and fruit set was poor (Weinberger, 1950a). The minimum number hours that resulted in normal bloom was termed the "chilling requirement" for the cultivar. Originally cultivar chilling requirement was determined by forcing twigs at intervals during the winter and noting if 50\% budbreak occurred in 3 weeks (Weinberger, 1950a), but in recent years, chilling requirement of an unrated cultivar has often been estimated by bloom time relative to that of known adapted cultivars. Peach cultivars with the same chilling requirement will usually bloom at approximately the same time. The chill hour model is easy to understand and calculate and is still commonly used, especially to describe cultivar chilling requirement (Okie, 1998). Although "chill hours" are defined as distinct from "chill units," these terms are often used interchangeably, particularly when used to rate cultivar chilling requirement.

Utah weighted chill units (cu) were initially defined by a rough step function (Richardson et al., 1974; Seeley, 1996). One $\mathrm{h}$ in the optimum chilling temperature range was defined as $1 \mathrm{cu}$ with suboptimal temperatures counting less. This step function was subsequently refined into a series of three curves representing shelter, bud, and effective temperatures (Anderson et al., 1986; Richardson et al., 1986; Seeley, 1996). More recent studies with other crops have suggested that slightly higher and lower temperatures than they included as effective may also have some chilling effect (Harrington et al., 2010; Mahmood et al., 2000). The Utah chilling models assume warm temperatures negate previous chilling regardless of when it occurred, a concept refuted by comparisons of controlled temperature cycles (Couvillon and Erez, 1985a). Because unlimited negation is problematic in milder climates, some have adapted the Utah models by limiting or even ignoring the chill negation (Allan

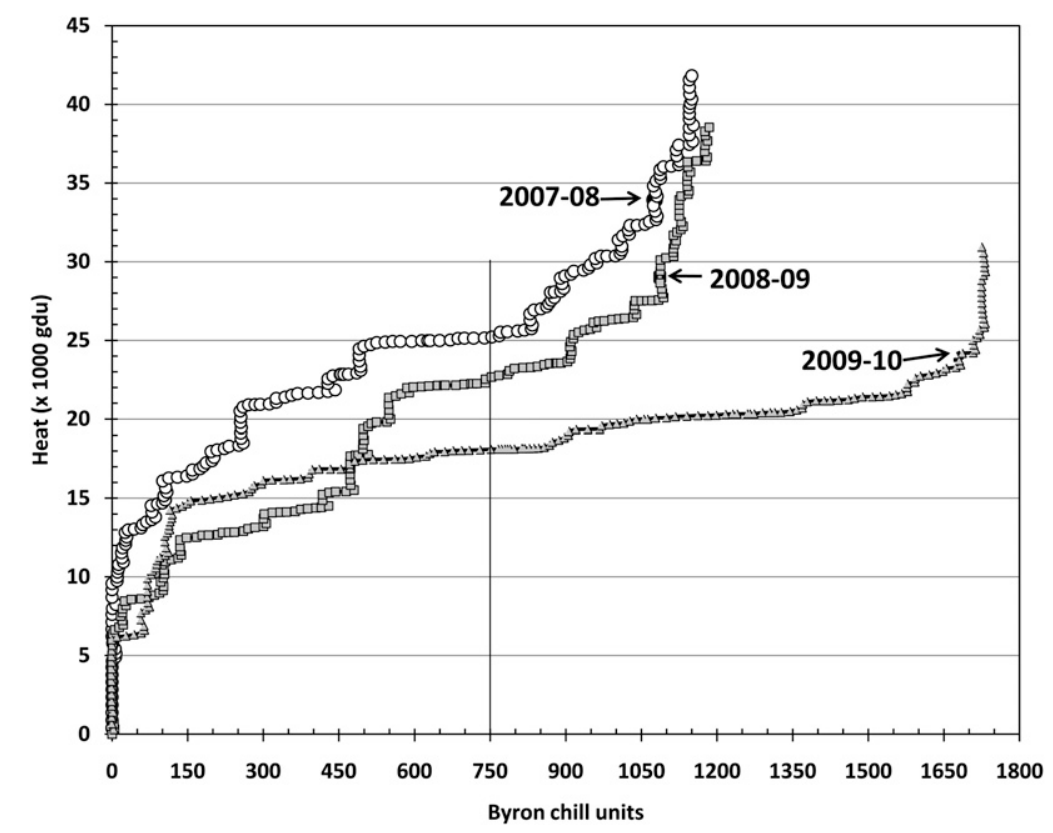

Fig. 1. Daily winter heat [gdu (growing degree units) from base $4{ }^{\circ} \mathrm{C}$ ] and chilling (bcu) accumulations from 1 Oct. at Byron, GA, for 3 years. Each point represents one day. Vertical line at 750 bcu represents chilling requirement for 'Sunland'. Arrows show 50\% bloom dates for 'Sunland': 15 Mar. 2008, 10 Mar. 2009, and 21 Mar. 2010. bcu = Byron chill units. 
et al., 1995; Linsley-Noakes et al., 1995). The Dynamic Model has a similar adjustment, making accumulated chilling irreversible if cool temperatures follow the chilling. In Byron, GA, a modified Utah curve, close to that described by Anderson et al. (1986) with negation limited to the chilling received that day or the previous day, has generated chill units that track Dynamic Model chilling portions most years at a ratio of 20:1 (Okie, 1998). These chill units will also track chill hours in years in which hours at temperatures greater than $7{ }^{\circ} \mathrm{C}$ and less than $12.5^{\circ} \mathrm{C}$ (not counted as "hours") roughly match those either less than $6{ }^{\circ} \mathrm{C}$ (overcounted as "hours") or $7{ }^{\circ} \mathrm{C}$ or less and later negated (counted as "hours").

A later version of the Utah model included a heat accumulation component (Richardson et al., 1986), allowing a prediction of bloom time, in contrast to the previous models, which addressed only the chilling component. Reported chilling requirements for 'Elberta' and 'Redhaven' were 800 and $870 \mathrm{cu}$, respectively, after which exposure to 4200 growing degree units (gdu; $4{ }^{\circ} \mathrm{C}$ base temperature) would result in bloom. This simplified model of the dormancy breaking process has been useful in cold climates. In milder climates, it is inadequate in some years, which is not surprising considering that typical winter weather patterns often result in both heat and chill units on the same day. Some of these issues with the model have since been recognized (del RealLaborde et al., 1990; Seeley, 1996). Furthermore, to get maximum budbreak from buds exposed to artificially supplied, constant chilling requires substantially more hours or units than these figures suggest (Freeman and Martin, 1981). Note that in the initial paper (Richardson et al., 1974), the Utah team held the cuttings at "low" temperatures after chilling and before forcing, which may have provided additional chilling. Also, the Utah model starts accumulating chilling when negated chilling reaches the lowest (most negative) value in the fall, but this idea makes more sense in a cold climate where winter has a more clear-cut beginning (Seeley, 1996). Further work is needed to clarify what factors such as temperature and daylength (Jimenez et al., 2010) trigger the change from ecodormancy or paradormancy to endodormancy in fall and thus when chill unit accumulation should begin.

The influence of chilling accumulation on the amount of heat accumulation required for budbreak was perhaps first noted by Hutchins (letter to E.C. Auchter, 1 Feb. 1937): "When something more than half of the necessary hours of cold for a variety have been accumulated, the tree may come tardily into bloom with continued warmth.... Each day of necessary cold after the minimum development has been reached will shorten the period of lag in development of flower buds exposed to warmth by a time corresponding roughly with the duration of cold so received." Thirty years later, Rom and Harrington (1966) showed increased chilling of 'Elberta' peach reduced heat-days to budbreak. Others (Couvillon and Erez, 1985b; Couvillon and Hendershott,
1974) found that "post-rest" chilling in the orchard reduced heat accumulation to budbreak for several peach cultivars, but it is not clear how much heat was accumulated before the twigs were cut from the orchard and forced. Scalabrelli and Couvillon (1986) compared artificial chilling of 'Redhaven' peach $(950 \mathrm{cu})$ for 600,1340 , and $2040 \mathrm{~h}$. The first increment increased floral budbreak and reduced heat accumulation to budbreak, but the second step increased budbreak only slightly more and did not affect heat required. Gariglio et al. (2006) studied several mostly lowchilling cultivars of peaches by exposing them to artificial chilling in 100-h increments before forcing. As chilling increased, time to budbreak decreased. However, their cuttings were single bud segments with no terminal bud, which may not behave as do buds on intact shoots. Chilling was also negatively correlated with heat accumulation to budbreak for ornamental and Brazilian peaches (Citadin et al., 2001; Pawsut et al., 2004). Similar relationships have been reported for other crops including apple (Malus $\times$ domestica Borkh.), cherry (Prunus cerasus L.), and forest trees (Andersen, 1991; Cannell and Smith, 1983; Couvillon and Erez, 1985b; Felker and Robitaille, 1985; Hauagge and Cummins, 1991; Landsberg, 1974). Harrington et al. (2010) described an exponential curve relating chilling and heat accumulation to vegetative budbreak in a group of experiments with Douglas fir [Pseudotsuga menziesii (Mirb.) Franco] seedlings. They proposed that budbreak was only possible when the combination

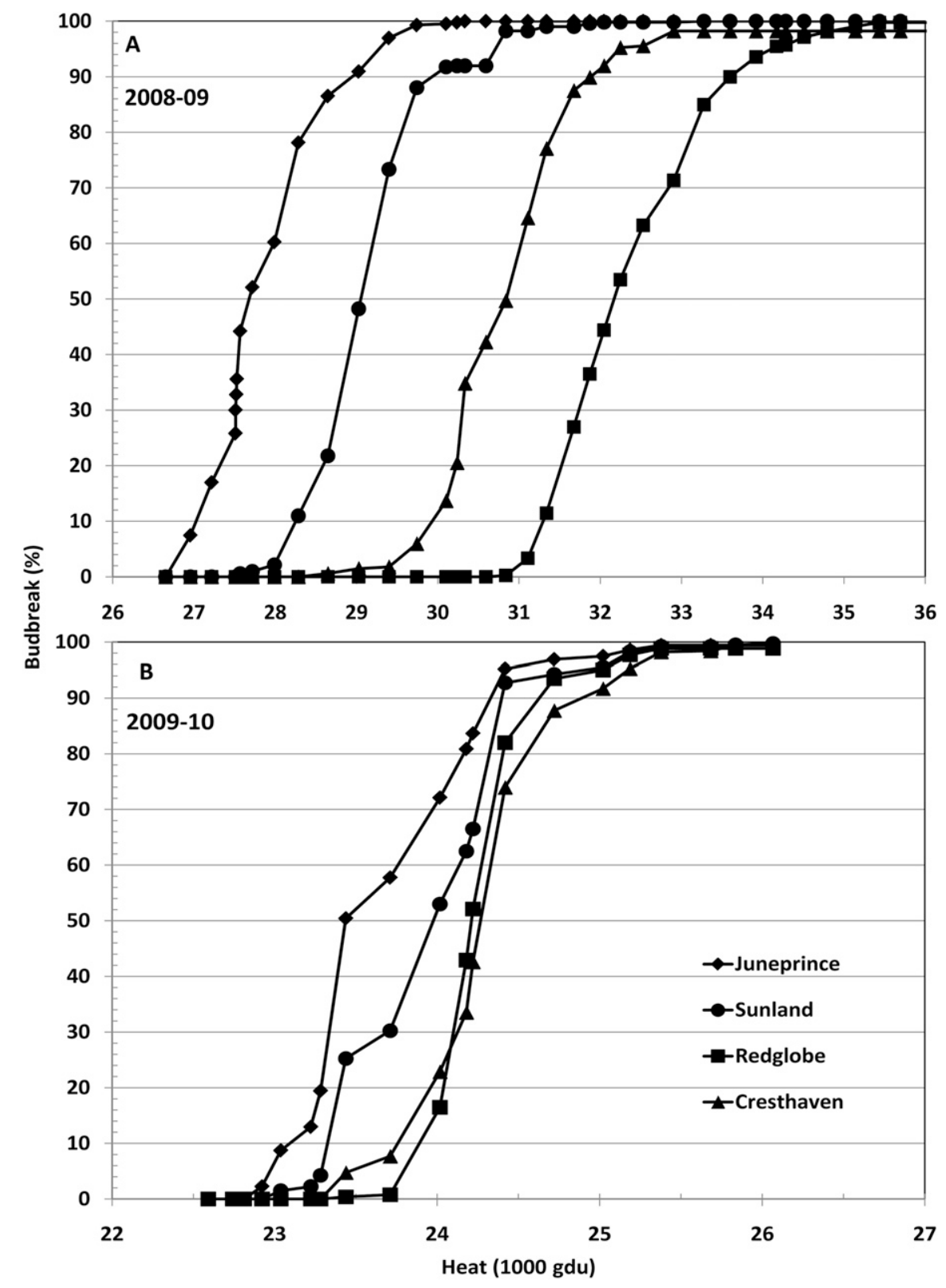

Fig. 2. Cumulative orchard bloom versus accumulated heat units for 'Juneprince', 'Sunland', 'Redglobe', and 'Cresthaven' peaches at Byron, GA, in 2009 (A) and 2010 (B). Values represent means of four trees with five twigs per tree. Points represent daily observations plotted based on the heat received each day. Heat accumulation starts 1 Oct. and uses $4{ }^{\circ} \mathrm{C}$ base temp. 
of chilling and heat accumulation was on this "possibility line" or at a point where both chilling and heat were either equal or greater than a point on the line. Linkosalo et al. (2006) used the terms "sequential" and "parallel" to describe different approaches to dormancy and budbreak models. The more common sequential models such as the Utah model require chilling to be satisfied before development proceeds. In contrast, the less common parallel approach assumes that the amount of chilling affects the amount of heat required, because the processes can overlap.

Because this curvilinear relationship between chilling and heat requirement has been little studied in commercial peaches, yet appears critical to modeling bloom in areas with mild winters, we studied the effects of increasing chilling on peach floral budbreak in three ways: 1) natural bloom in the orchard; 2) weekly sets of cuttings forced in uniform conditions; and 3) incremental supplemental chilling of cuttings followed by forcing.

\section{Materials and Methods}

Mature trees for these experiments were grown at the USDA-ARS Southeastern Fruit and Tree Nut Research Laboratory in Byron, GA (lat. $32.7^{\circ} \mathrm{N}$, long. $83.7^{\circ} \mathrm{W}$, elev. $160 \mathrm{msl}$ ) and managed following commercial recommendations. Orchard temperatures during the winter were recorded every $15 \mathrm{~min}$ in a weather shelter located $\approx 2 \mathrm{~km}$ from the orchard. Chilling accumulation was estimated from these temperatures starting 1 Oct. by calculating Byron chill units (bcu), which used an approximation of the Utah model "effective chilling temperature" curve (Anderson et al., 1986), but in which high temperatures negated only the current and previous day's chilling. Heat accumulation from 1 Oct. was estimated by calculating gdu above $4{ }^{\circ} \mathrm{C}$, based on an approximation of the published curve (Anderson et al., 1986).

Orchard bloom. In springs 2009 and 2010 , bloom on the trees was monitored for cultivars Juneprince (650 cu requirement), Sunland (750), Redglobe (850), and Cresthaven (950). Although chill hour requirements are not strictly convertible to chill units, we used them as reference points for lack of a better system. Five twigs on each of four trees were observed daily beginning 26 Feb. in 2009 and 12 Mar. in 2010. Open blossoms were counted and removed. Daily bloom values were presented as a function of heat units (gdu) to standardize the data. A hypothetical normal curve was generated for 650 and $750 \mathrm{cu}$ peaches using a normal distribution probability function with means of 650 or 750 and SD of 50. In a normal curve, $95 \%$ of the points are within 2 sDs of the mean. Experience showed a range of $\approx 200 \mathrm{cu}$ encompassed the majority of buds of a typical cultivar, which suggested a SD of 50 was reasonable. Five chill unit increments were used to generate the normal cumulative distribution function. These increments were combined into $25 \mathrm{cu}$ increments to generate the normal distribution probability function showing the hypothetical proportion of buds in each chilling range.

Cuttings sampled weekly. Upright twigs of the previous season's growth of 'Sunland' were cut weekly from the trees beginning 100 to $150 \mathrm{bcu}$ below the rated chilling requirement and continuing until natural budbreak. Twigs were basally trimmed to $\approx 30 \mathrm{~cm}$ length and a basal diameter of $\approx 4$ to $5 \mathrm{~mm}$. Twigs were placed singly in $25 \times 95$-mm polystyrene Drosophila vials (VWR International, West Chester, PA). Each treatment consisted of a rack of 12 twigs per cultivar. Vials were filled with Floralife Crystal Clear (Floralife Inc., Walterboro, SC) at double strength $(2 \times=$ $32 \mathrm{~mL} \cdot \mathrm{L}^{-1}$ water; $\mathrm{pH}=2.78$; soluble solids $=$ $1.4 \%$ ). Crystal Clear contains no hormones and did not affect the rate of budbreak in comparison with water but did reduce bacterial growth in the water and extend twig viability (data not shown). For bud forcing, racks of twigs were placed in unreplicated growth chambers (I-66VL incubator; Percival Scientific, Perry, IA) maintained at $18.3 \pm 1{ }^{\circ} \mathrm{C}$ and illuminated for $12 \mathrm{~h}$ in a diurnal cycle using fluorescent light (F32T8 TL741 Alto; Phillips Lighting, Somerset, NJ). The $18.3{ }^{\circ} \mathrm{C}$ temperature was chosen to be high enough to avoid further chilling accumulation yet low enough to allow maximum budbreak. Temperatures within the chambers were recorded using Hobo
H08-030-08 data loggers (Onset, Bourne, MA). Each day, twigs were briefly removed from the forcing chambers for rating. Flower buds showing green scales ("green eye") were considered broken, counted, and removed. Bud removal extended twig life and greatly reduced the time needed to rate the twigs each day. Vegetative buds were left intact. After 5 to 6 weeks, the remaining flower buds (based on location and shape) were counted to calculate percent budbreak.

Supplemental chilling of cuttings. Twigs were prepared as described previously. 'Sunland' twigs were cut in 2008 on 18 Jan. (612 bcu) and given an additional 1, 2, 3, 4, 5, 6, 7, 8, $10,14,22$, or $38 \mathrm{~d}$ chilling at $4 \pm 1{ }^{\circ} \mathrm{C}$ in a dark growth chamber. In 2009 they were cut 2 Jan. (543 bcu) and given 4, 6, 8, 11, 12, 16, 20, 28, or $36 \mathrm{~d}$ additional chilling. 'Flordaprince' was cut 2 Nov. 2007 (21 bcu) and given 0, 6, 8, 10, $12,14,16$, or $21 \mathrm{~d}$ chilling. 'Flordadawn' was cut 14 Nov. 2008 (65 bcu) and given 0, 2, 5, 6, $8,12,16,26$, or $32 \mathrm{~d}$ chilling. 'Goldprince' was cut 16 Nov. 2007 (90 bcu) and given 19, 23, 29, 37 , or $50 \mathrm{~d}$ chilling. 'Juneprince' was cut 16 Nov. 2007 (90 bcu) and given 19, 21, 23, 25, $29,33,37,44,50$, or 56 d chilling. To estimate the starting date of effective orchard chilling, chilling satisfaction of 'Flordaprince' (the lowest chilling cultivar at Byron requiring only $150 \mathrm{cu}$ ) was monitored by forcing cuttings

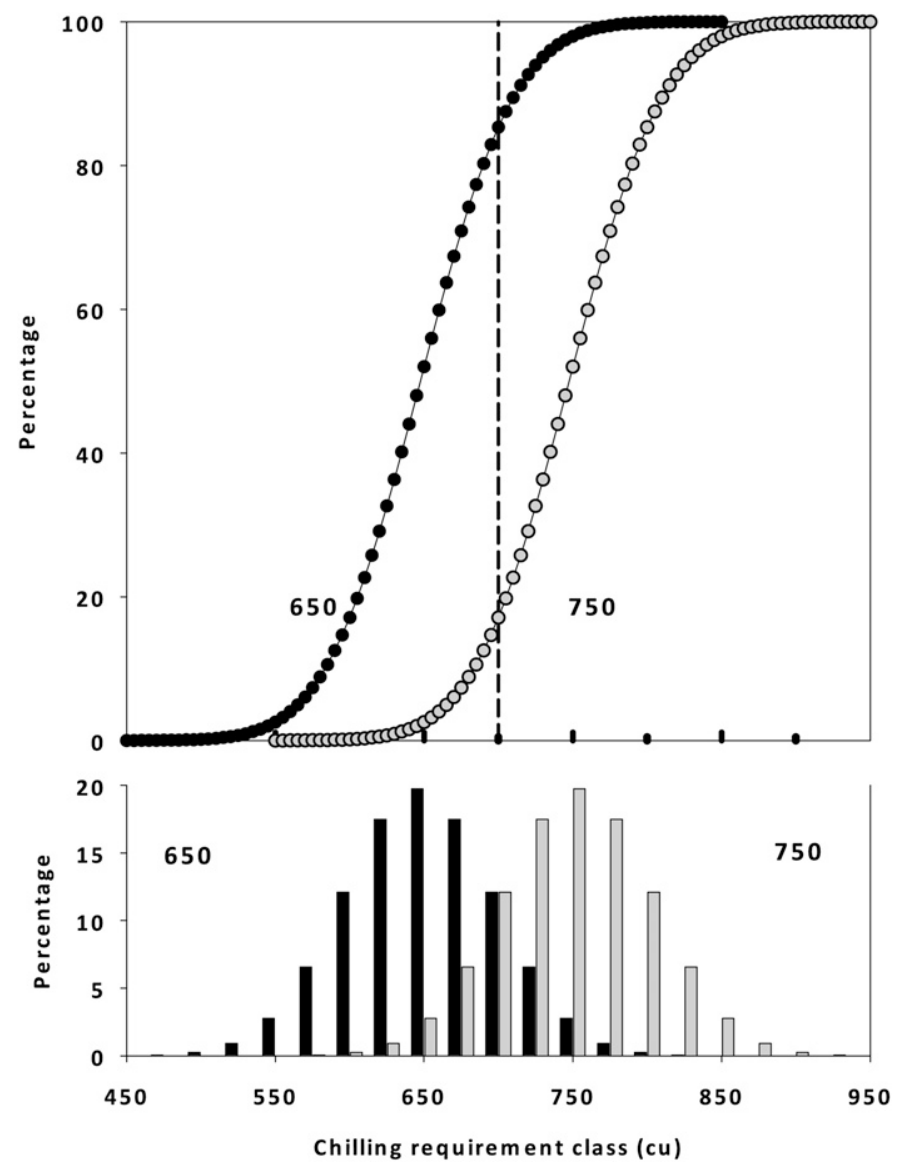

Fig. 3. Hypothetical distributions of individual bud chilling requirement. Based on standard normal curves with means of 650 or $750 \mathrm{cu}$ and sDs of $50 \mathrm{cu}$. Bars show percentage of buds in each $25 \mathrm{cu}$ class. Cumulative curves show percentage of total buds as chill unit requirement increases in $5 \mathrm{cu}$ increments. Dashed line shows curve overlap. $\mathrm{cu}=$ chill units. 
collected weekly. When budbreak reached $50 \%, 150 \mathrm{bcu}$ was assumed to have occurred. As a result, chilling accumulation was adjusted in 2007-2008 $\times 0$ units, in 2008-2009 by -70 units, and in 2009-2010 by -120 units. Forcing was done as described previously. TableCurve (Systat, Richmond, CA) was used to fit an exponential curve to the adjusted data.

\section{Results}

Orchard bloom. Figure 1 shows the varied patterns of heat accumulation and chilling during the last three winters at Byron, GA. The vertical line marks $750 \mathrm{bcu}$, the estimated chilling requirement of 'Sunland'. Arrows indicate timing of $50 \%$ bloom for 'Sunland' in each year. The first two winters were typical for the area. The stair step pattern is the result of cold and warm spells that lasted several days each. By the traditional critical chilling date of 15 Feb., chilling had reached 896 bcu in 2007-2008 and 925 bcu in 2008-2009. The 2009-2010 winter was unusual for the large amount of chilling that was received without intervening warm spells. By 15 Feb., chilling had reached 1289 bcu. From 750 bcu to 50\% bloom took 8352 gdu in spring of 2008, 6362 gdu in 2009, and 5869 gdu in 2010; heat accumulation was inversely proportional to the chilling received by $15 \mathrm{Feb}$.

Figure 2 shows how the pattern of chilling translated to timing of bloom. In Spring 2009 (Fig. 2A), the four cultivars bloomed sequentially with minimal overlap. When a cultivar had $10 \%$ to $15 \%$ of its flowers yet to open, the next higher chilling cultivar had $10 \%$ to $15 \%$ open. Each cultivar bloomed over $\approx 3000 \mathrm{gdu}$ with $\approx 8000$ gdu total span for all four cultivars. The initial $20 \%$ of bloom for a given cultivar occurred in a shorter span than the final $20 \%$ of bloom. In Spring 2010 (Fig. 2B), after extensive chilling interspersed by minimal heat, the entire bloom required only 3000 gdu with $\approx 1000$ gdu per cultivar and substantial overlap in bloom between cultivars. Note that Figure $2 \mathrm{~B}$ has an $\mathrm{x}$-axis range half that of Figure 2A.

Heat accumulation during the interval between reaching $650 \mathrm{bcu}$ and $750 \mathrm{bcu}$ varied between years at 225,526 , and 148 gdu for 2007-2008, 2008-2009, and 2009-2010, respectively (Fig. 1). Under a sequential model one would expect the heat for this interval to be similar to that between the times of bloom for the same cultivars. However, the heat accumulated between $50 \%$ bloom for 650 versus $750 \mathrm{cu}$ cultivars was 1263,1309 , and $579 \mathrm{gdu}$ for the same 3 years.

Figure 3 (bars) shows hypothetical normal curve distributions of individual bud chilling requirement classes for 650 and $750 \mathrm{cu}$ cultivars. The vertical line on the cumulative curves shows how the chilling requirements of individual buds of the two cultivars would overlap. Approximately $15 \%$ of the buds of the $650 \mathrm{cu}$ cultivar required $700 \mathrm{cu}$ or more, whereas $15 \%$ of the buds of the 750 cu cultivar required less than $700 \mathrm{cu}$. This overlap in bloom classes is similar to the overlap in actual field bloom in 2009 (Fig. 2A).
Cuttings sampled weekly. As chilling increased over subsequent weeks, budbreak started and progressed faster and reached higher percentages. At the first cutting date, 16 Jan. 2009 (at 588 bcu), budbreak was slow and never reached 50\% (Fig. 4A). Budbreak curves from 16 Jan. and 23 Jan. overlapped in time initially but later diverged as additional buds broke on the later set. Results were similar in 2007-2008 (data not shown). In 2010 (Fig. 4B), budbreak of four of the six sets began $\approx 27$ Jan. Rate and maximum percentage of budbreak generally increased with chilling. If these data were plotted on a heat accumulation basis (like in Fig. 5A) rather than by date, the individual curves would be shifted proportionately to the left reflecting the reduced heat to initial budbreak for each subsequent sampling date.

Supplemental chilling of cuttings. The confounding effects of orchard heat exposure on budbreak timing can be minimized by providing supplemental chilling to partially chilled cuttings. Additional chilling of 'Sunland' cuttings in 2007-2008 generally increased total budbreak (Fig. 5). Results in 2008-2009 were similar (data not shown). The first eight curves from the right (Fig. 5A) show the impact of single-day increments of chilling. The rate of budbreak increased with chilling as indicated by the increasing slope of the linear portion of the curve. Lines for the first two lowest chilling treatments overlapped, but each additional chilling increment clearly increased the slope of the curve. More chilling also shifted the curve to the left, indicating that less heat accumulation was needed (Fig. 5A). Replotting these data with dates rather than heat units on the $\mathrm{x}$-axis shows the inverse relationship between chilling and heat needed for budbreak resulted in a simultaneity of initial budbreak $\approx 9$ Feb. (Fig. 5B). The curves do separate to the right, because

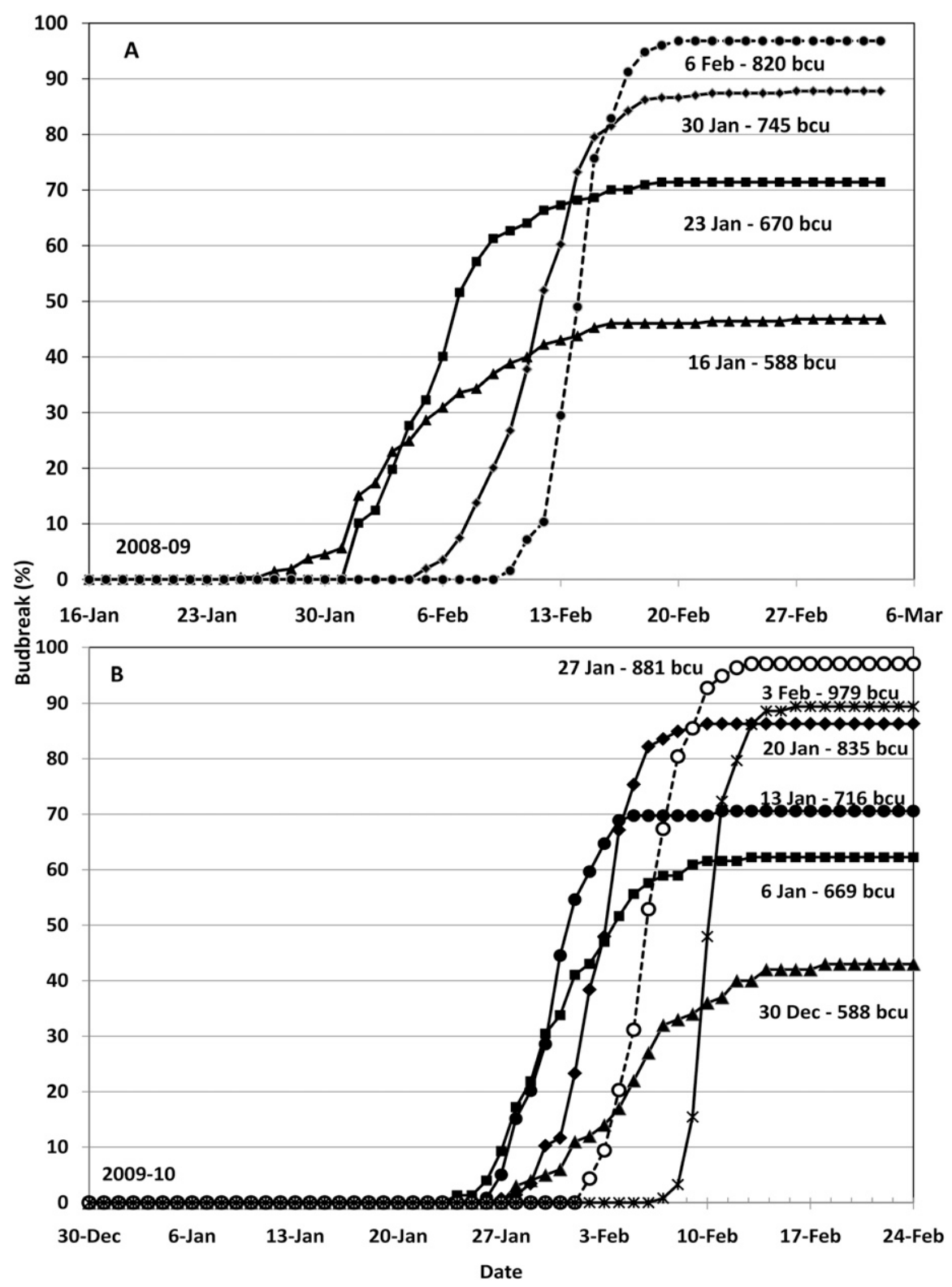

Fig. 4. Cumulative floral budbreak in cuttings of 'Sunland' sampled weekly and forced at $18.3{ }^{\circ} \mathrm{C}$. Twigs harvested beginning 16 Jan. 2009 (A) or 30 Dec. 2009 (B). Each point mean for 12 cuttings. 

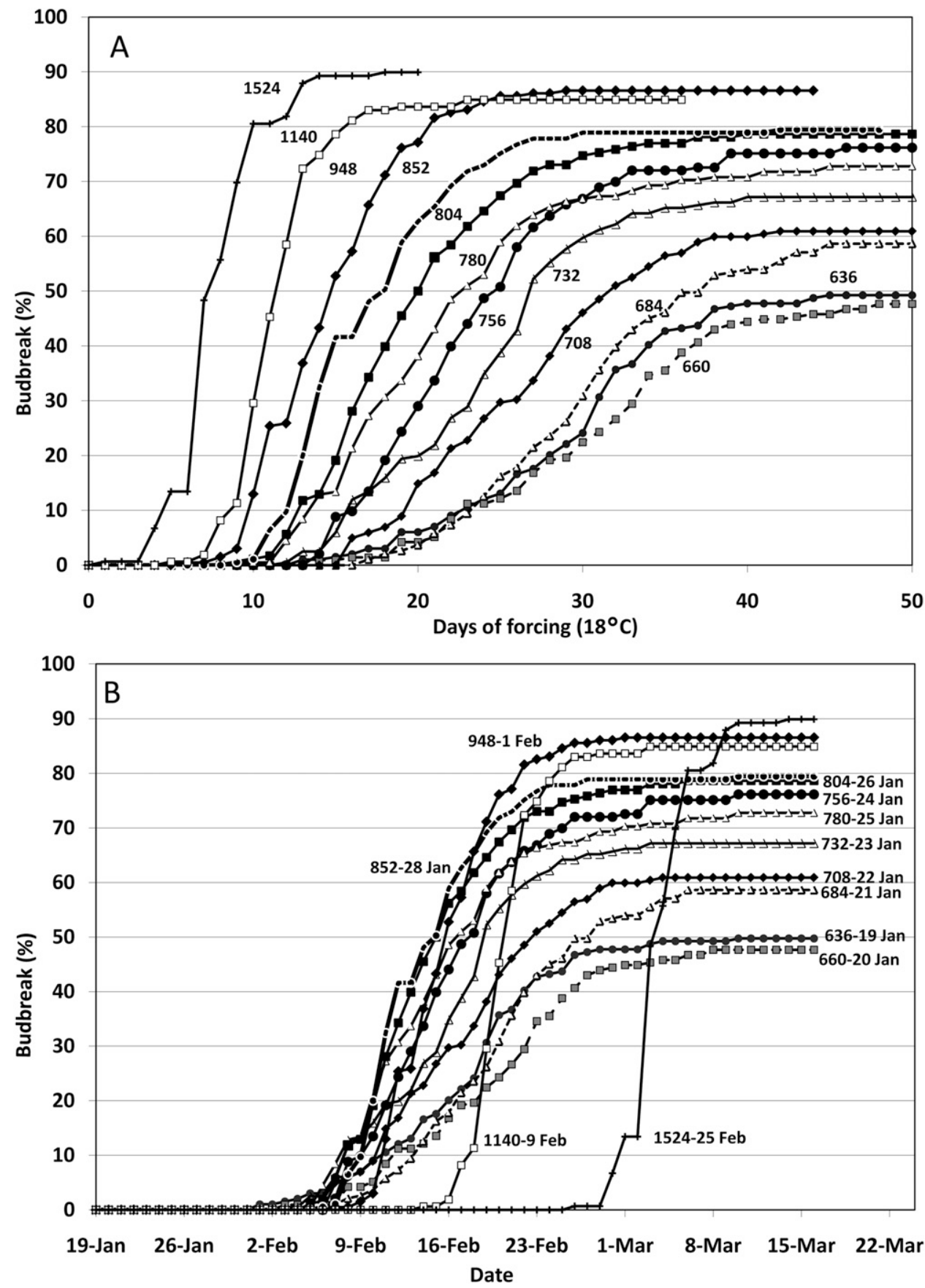

Fig. 5. Cumulative budbreak in 2007-2008 for 'Sunland' peach flower buds on twigs cut 18 Jan. 2008 and chilled at $4{ }^{\circ} \mathrm{C}$. Treatments are in increments of $1 \mathrm{~d}$ of chilling except for last four treatments, which are 2, 4, 8, and $16 \mathrm{~d}$ increments. (A) X-axis as days of forcing at $18.3^{\circ} \mathrm{C}$. Curve labels show chilling received. (B) $\mathrm{X}$-axis as date of budbreak, which includes chilling time. Labels show chilling treatment and date moved to forcing.

the higher chill-requiring buds break sooner on the treatments receiving higher amounts of chilling. Budbreak in the two highest chilling treatments were delayed relative to the other treatments; the additional 8 or $16 \mathrm{~d}$ of chilling produced little corresponding reduction in heat to budbreak.

Expressing the same data in terms of forcing days to $50 \%$ budbreak showed that increased chilling reduced the time and thus the heat accumulation needed for budbreak (Fig. 6). When bcu values were normalized for starting date by 'Flordaprince' budbreak and expressed as relative to the $750 \mathrm{cu}$ requirement for 'Sunland', patterns were very similar in 2008 and 2009. An exponential decay curve fitted over both years $\left(r^{2}=0.949\right)$ had the form: days to budbreak $=a+b \times \mathrm{e}^{(- \text {chill/c) }}$, where $\mathrm{a}=10.47, \mathrm{~b}=13.22$, and $\mathrm{c}=108.18$.

Term $a$ is the baseline value when chilling is infinite, whereas terms $b$ and $c$ define the shape of the curve. This exponential relationship shows that the initial increases in chilling (left to right in graph) result in dramatic decreases in heat needed. It is surprising to see how much effect a single additional day of chilling can have on heat to budbreak for these marginally chilled buds. The curve can be divided into three sections. The steeply negative slope of the leftmost section indicates each additional day of chilling reduced heat to budbreak by multiple days. Total days (Fig. 6 , open circles), which are days at supplemental chilling plus forcing days, initially decline. In the intermediate section, starting at $\approx+50$ on the $\mathrm{x}$-axis, the slope is $\approx-1$ (if $\mathrm{x}$-axis units were changed to days of chilling). Total days remain nearly constant until $\approx+200$ chill units and approximate the $1: 1$ substitution ratio that Hutchins described. In the section above +200 $\mathrm{cu}$, the slope approaches zero; total days begin to increase because further chilling simply delays bloom with little or no reduction in the amount of heat needed. Curves showing time to reach $30 \%$ and $70 \%$ budbreak (data not 
shown) were similar to the $50 \%$ line in Figure 6 but slightly offset down and left, or up and right, respectively, suggesting each class (by chilling requirement) of buds follows a similar curve.

The relationship between chilling and forcing days to budbreak was similar for the other cultivars tested (Fig. 7). Budbreak did not reach $50 \%$ for the following treatments:
'Flordaprince', 0 and 6 d; 'Flordadawn', 0, 2, 5 , and $6 \mathrm{~d}$; and 'Goldprince', $0 \mathrm{~d}$. A fitted exponential curve (Fig. 7) was similar to the curve for 'Sunland' (Fig. 6), although the coefficients were different. The deviation in the data for 'Goldprince' and 'Juneprince' may relate to the fact that they received much more of their chilling artificially than did the other cultivars.

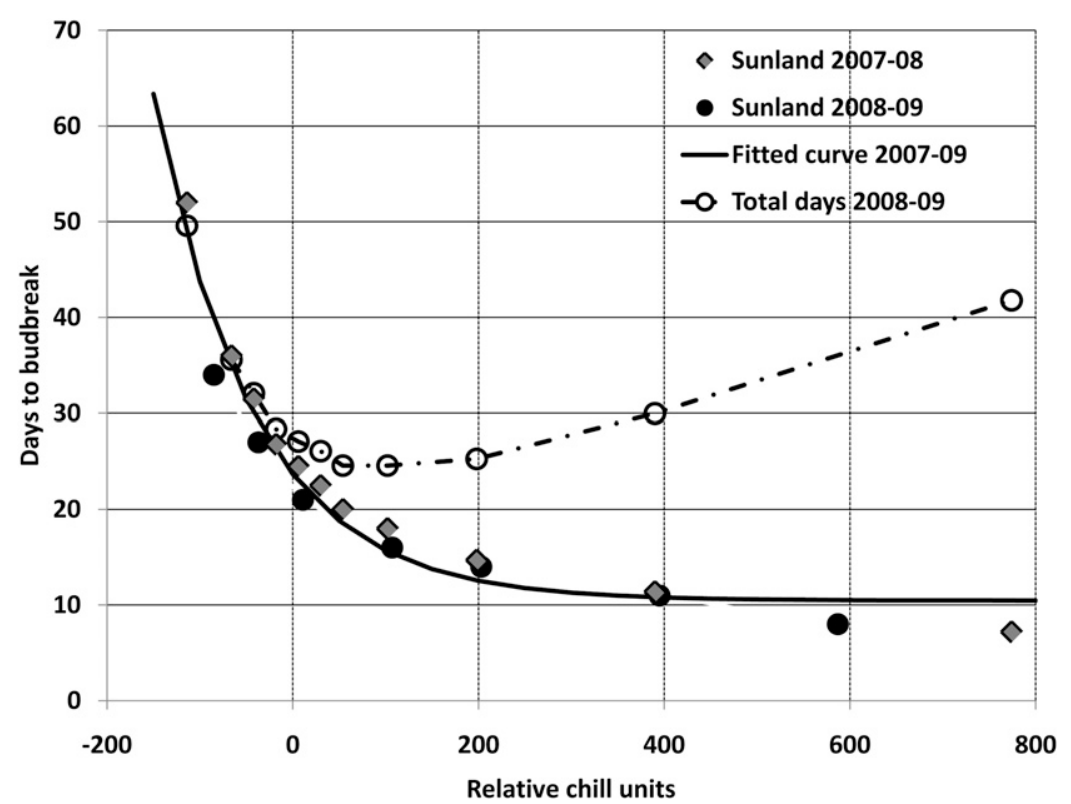

Fig. 6. Effect of chilling $\left(4^{\circ} \mathrm{C}\right)$ on days to 50\% flower budbreak for 'Sunland' peach in 2007-2008 (gray diamonds) and 2008-2009 (black circles). Open circles show total days (time chilling + time forcing at $18.3{ }^{\circ} \mathrm{C}$ ) for $2007-2008$. X-axis chilling is relative to $750 \mathrm{cu}$ rating for 'Sunland'. Fitted curve in the form: days to budbreak $=\mathrm{a}+\mathrm{b} \times \mathrm{e}^{(-\mathrm{chill} / \mathrm{c})}$, with $\mathrm{a}=10.47, \mathrm{~b}=13.22$ and $\mathrm{c}=108.18 ; r^{2}=0.95$. Chilling values for 2008-2009 adjusted by -70 bcu. $\mathrm{cu}=$ chill units; bcu = Byron chilling units.

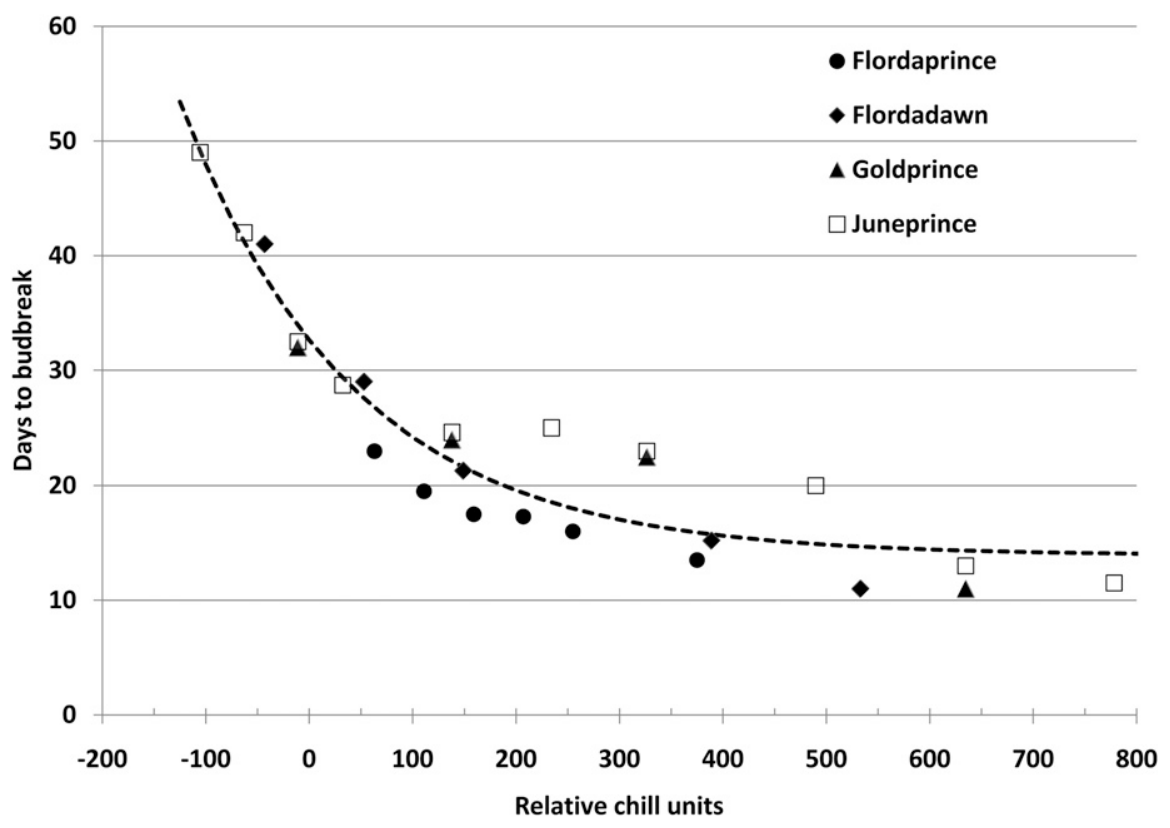

Fig. 7. Effect of chilling $\left(4^{\circ} \mathrm{C}\right)$ on days to $50 \%$ flower budbreak for peaches 'Flordaprince' (rated $\left.150 \mathrm{cu}\right)$ in 2007-2008, 'Flordadawn' (300 cu) in 2008-2009, 'Goldprince' (650 cu) in 2007-2008, and 'Juneprince' $(650 \mathrm{cu})$ in $2007-2008$. Forcing temperature was $18.3^{\circ} \mathrm{C}$. X-axis chilling is relative to cultivar chilling rating. Fitted curve in the form: days to budbreak $=\mathrm{a}+\mathrm{b} \times \mathrm{e}^{(-\mathrm{chill} / \mathrm{c})}$, with $\mathrm{a}=13.906464, \mathrm{~b}=18.735617$, and $\mathrm{c}=167.48784 ; r^{2}=0.89$. Chilling values for 2008-2009 adjusted by $-70 \mathrm{bcu}$. cu $=$ chill units; bcu $=$ Byron chilling units.

\section{Discussion}

These results suggest that the flower buds of a given cultivar vary substantially in chilling requirement. Although the cause of this variability is unknown, a range in chilling requirement can extend bloom, which increases the chances of fruit set in a moderate climate with spring frosts. Younger, less mature buds (such as on the ends of vigorous watersprout growth) do bloom later, but the majority of flower buds on shorter twigs are set by midsummer in our climate. We did not make detailed notes on the order of bloom on a twig. Although Spencer and Couvillon (1975) found a trend in bloom from distal to proximal, our observations indicate the specific order is quite variable.

The class overlap in the hypothetical cumulative curves (Fig. 3 ) is similar to that seen in orchard bloom in 2009 (Fig. 2A). The shape of the orchard bloom curves will vary depending on the chilling and heat patterns, but the amount of overlap should be independent of the weather patterns, because it results from buds with similar chilling requirements (assuming each bud acts independently). However, a high-chilling year can obscure the overlap if extensive chilling causes buds with a wide range of chilling requirement to bloom together, like in 2010 (Fig. 2B). Other work (Gariglio et al., 2006; Landsberg, 1974; Scalabrelli and Couvillon, 1986) has shown that increasing chilling increases percentage budbreak, but the impact of a wide range in chilling requirements on bloom patterns has been largely ignored.

With the Utah model, differences in time of bloom (based on heat accumulation, not date) between cultivars should reflect the amount of heat that occurred during the completion of chilling by one cultivar and the next. In our work, differences in heat accumulation at chilling completion were two to six times smaller than differences in heat during bloom, which suggests a sequential model of chilling and forcing is inadequate in this climate. The highest chilling year, 2009-2010, had the least difference between heat accumulation at chilling completion and that at bloom (431 gdu). Furthermore, using the chilling received by 15 Feb. as a measure of winter chilling, the lowest chilling winter (2007-2008) had the highest heat accumulation from completion of $750 \mathrm{bcu}$ until bloom, whereas the highest chilling year (2009-2010) had the lowest (Fig. 1).

Figure 6 plots the time to budbreak for the middle cohort of buds (presumably requiring $750 \mathrm{cu}$ in Fig. 3) in response to increasing chilling, because $50 \%$ overall is reached at the time that cohort breaks bud. If we take all of the hypothetical classes of bud chilling requirement for a cultivar requiring $750 \mathrm{cu}$ (Fig. $8 \mathrm{~A}$ ) and expose them to 650,750 , or $950 \mathrm{cu}$, we can use the formula from Figure 6 to predict how many days of heat are required for budbreak for each class after each amount of chilling (Fig. 8B). After 750 cu exposure, buds in the $650 \mathrm{cu}$ class would have $+100 \mathrm{cu}$ over their "requirement" and reach budbreak in $\approx 16 \mathrm{~d}$. Buds in the 650 to $750 \mathrm{cu}$ requirement classes would encompass a small range in days 

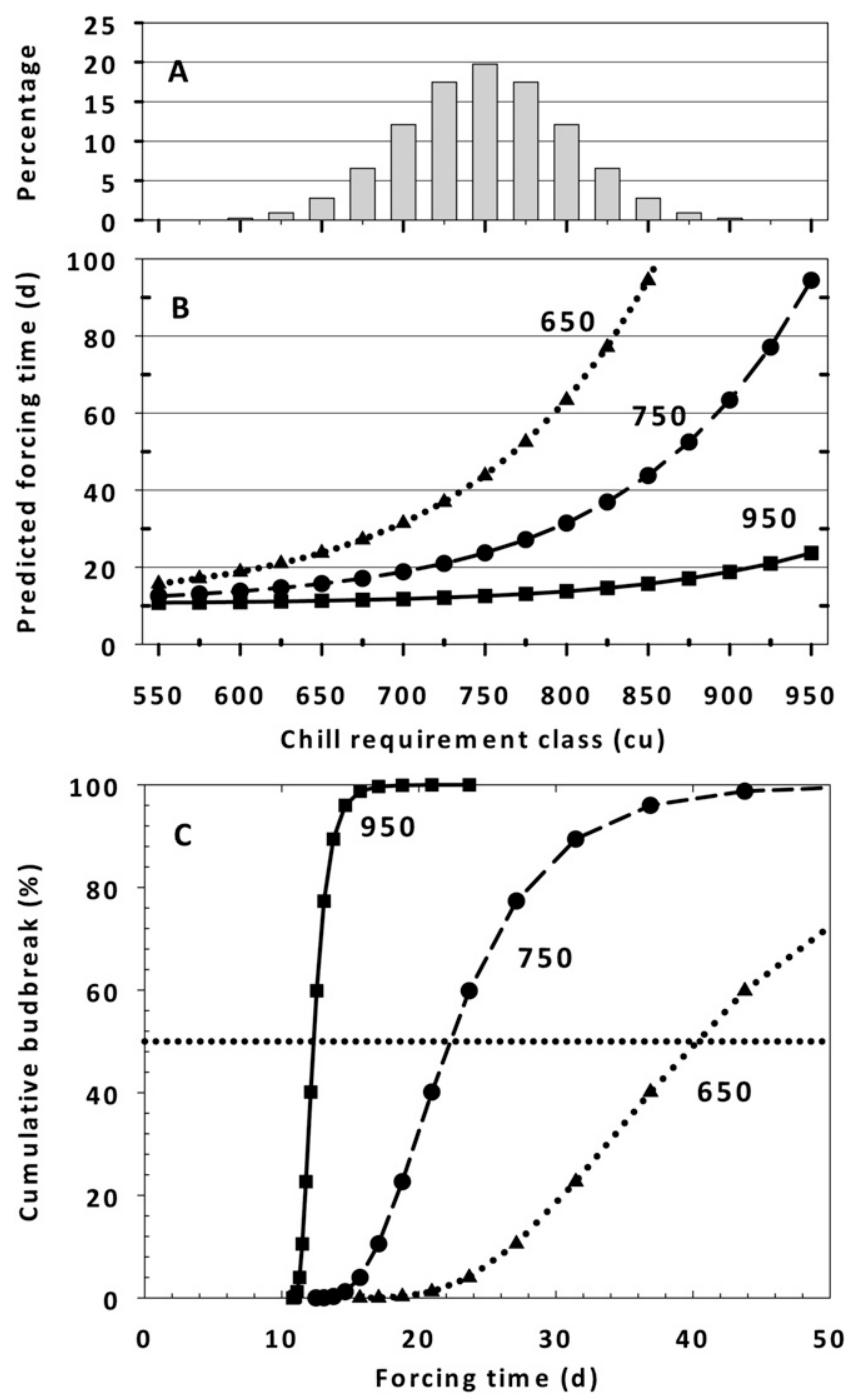

Fig. 8. Hypothetical distribution of buds by chilling unit requirement (A) based on standard normal curve with mean chilling requirement of $750 \mathrm{cu}$ and SD of $50 \mathrm{cu}$. Predicted forcing time (B) for each bud class after exposure to 650,750 , or $950 \mathrm{cu}$. Predicted cumulative budbreak (C) for the same buds after exposure to 650,750 , or $950 \mathrm{cu}$. $\mathrm{cu}=$ chill units

to budbreak, because the curve for $750 \mathrm{cu}$ flattens out to the left (Fig. 8B). The predicted time to budbreak for buds above the median increases rapidly with $\approx 45 \mathrm{~d}$ needed for those in the $850 \mathrm{cu}$ class (Fig. 8B). On the $750 \mathrm{cu}$ cumulative curve (Fig. $8 \mathrm{C}$ ), $50 \%$ budbreak is reached within $22 \mathrm{~d}$ of forcing. Half the buds (chilling requirement greater than $750 \mathrm{cu}$ ) lack enough chilling to break within $22 \mathrm{~d}$. Thus, Figure $8 \mathrm{~B}-\mathrm{C}$ shows that in a lower chilling year (650 cu line), 'Sunland' budbreak would be skewed with the early bloom more concentrated and the later bloom more extended in terms of heat to budbreak. In contrast, in a high chilling year such as after $950 \mathrm{cu}$, most buds have at least $+100 \mathrm{cu}$ more than their requirement. The total range in days to budbreak is only a few days (Fig. $8 \mathrm{~B}-\mathrm{C}$ ), as is typical in a high-chilling year.

The chilling requirements for most of the buds on 'Sunland' twigs appear to be in the $750 \pm 100$ bcu range (Fig. 2A). Bloom curves from 2009 (Fig. 2A) showed a longer tail to the right as would be predicted (Fig. $8 \mathrm{C}$,
$750 \mathrm{cu}$ curve) for the less-well chilled buds. Bloom in 2010 (Fig. 2B) was more typical of bloom in colder climates and well-chilled buds (Fig. 2C, 950 cu curve). In that year, cultivars with a wide range in chilling overlapped in bloom. Thus, the hypothetical curves can produce a reasonable approximation of the actual field bloom data. The hypothetical budbreak curves (Fig. 8C) also approximate the series of curves from weekly cuttings (Figs. 4 and 5).

The exponential curve relationship, in combination with the range of chilling requirements among buds on a tree, can explain why bloom tends to be extended in moderate climates and concentrated in colder climates. They can also explain why we frequently find that weekly collections of twigs of a given cultivar all start to break with a few days of each other (Figs. 4-5) despite some being held inside and others outside. This apparent interchangeability of heat and chilling occurs in the 0 to $+200 \mathrm{cu}$ range of the curve (Fig. 6), in which the total days' curve is relatively flat. It is not clear if the exponential curves (Figs. 6-7) should flatten to a minimum parallel to the $\mathrm{x}$-axis. Buds on cuttings held for an extended time at $4{ }^{\circ} \mathrm{C}$ eventually break, suggesting the true heat base temperature may below $4{ }^{\circ} \mathrm{C}$ (data not shown; Seeley et al., 1996). The continued decline in the days-to-budbreak values after extended chilling (Fig. 6) may reflect slow heat gain even at $4{ }^{\circ} \mathrm{C}$. An understanding of the exponential curve in terms of changes in gene expression (Jimenez et al., 2010) as well as bud morphology (Reinoso et al., 2002) would be helpful in addressing such questions.

Harrington et al. (2010) suggested extending the exponential curve (their curve resembles that in Fig. 6) upward to the left to a point termed "critical cu," a minimum amount of chilling needed before the bud is responsive to heat. Our experimental set-up would not allow twigs to be forced much longer than 6 weeks. Trees in pots could be maintained in viable condition for a longer period, possibly extending the curve farther back. Bud forcing temperature is also likely a contributing factor. Budbreak of partially chilled twigs is less, although it proceeds faster, when twigs are forced at $25^{\circ} \mathrm{C}$ compared with $18{ }^{\circ} \mathrm{C}$ (data not shown). The critical cu level probably varies with forcing temperature. Orchard experience suggests underchilled buds can survive moderate temperatures better than extended high temperatures, which can cause bud abscission.

Harrington et al. (2010) also proposed that any combination of heat accumulation and chilling on or inside the curve could result in bloom. Presumably, in a climate like Oregon's, a tree could be approaching the curve and then be exposed to an extended cool spell, which delays bloom and moves it inside the curve. Subsequent warm temperatures would force it into bloom at chilling and heat accumulation values well inside the curve. However, in warmer climates, heat accumulation and chilling occur in a stair-step manner in the spring, often both on the same day. Heat occurring soon after the critical cu point is reached is likely to be less effective than heat occurring after extensive chilling. In fact, the reciprocal function for the curves in Figures 6 and 7 would be a measure of relative heat effectiveness as a function of chilling. Thus, heat is not likely to be additive, meaning the chill-heat combination at bloom would not be on the curve, although the curve could be useful in calculating the daily effectiveness of the heat.

In most chilling research, the buds are treated as homogenous. However in milder climates, differences in individual bud chilling requirement become more important. As the buds move through the chilling process, they are not all at the same stage and thus may respond differently to a given temperature. A temperature of $7{ }^{\circ} \mathrm{C}$ may reduce time to budbreak for a partially chilled bud but delay bloom for a highly chilled bud. Likewise, a $20{ }^{\circ} \mathrm{C}$ temperature could negate chilling of a partially chilled bud and slow development while hastening bloom for a well-chilled bud. Thus, experimental design and interpretation must be carefully done. 
This research undergirds the effort to develop peaches with higher heat requirement coupled with normal chilling requirement. Such peaches theoretically could bloom later in high-chilling years but still receive adequate chilling in low-chilling years (Citadin et al., 2001; Pawsut et al., 2004). Our initial screening showed that our understanding of the chilling process was inadequate to distinguish between delayed budbreak resulting from high heat requirement versus that resulting from suboptimal chilling. The exponential relationship between chilling and heat complicates the search for high heat requirement. Slow onset of budbreak and low rate of break indicate lack of chilling (Fig. 5). High heat requirement could shift the series of curves to the right, resulting in an exponential curve that is raised up with a higher baseline. Comparing budbreak curves such as in Figure 4 over several chilling levels would be needed to distinguish the patterns of different cultivars. Extended chilling must be done at relatively low temperature so that heat gain during chilling does not confound the results. However, lower temperatures are also thought to be less efficient for chilling, so the amount of chilling provided may be underestimated. Citadin et al. (2001) used a temperature of $2{ }^{\circ} \mathrm{C}$, which the Utah curve suggests is only $\approx 50 \%$ to $75 \%$ as effective for chilling as the optimum of $6{ }^{\circ} \mathrm{C}$. Genotypes with large numbers of flower buds might mimic high heat requirement by having more buds in the extreme classes of chilling requirement. The result could be enough buds able to survive and set a crop after either low-chill or highchill winters.

We suggest that bloom time is a function of the chilling status of the bud (i.e., where it is on the exponential curve or how responsive it is to heat) as well as the amount and timing of heat accumulated in the orchard. Once the critical cu has been reached, the relative proportions of chilling and heat that occur will influence how fast the bud proceeds to budbreak. Predominantly warm weather will produce an extended budbreak and the apparent amount of heat accumulation required will be large. If supraoptimal chilling is received without substantial heat, our approach simplifies into a semblance of the Utah model, and a minimum amount of heat is needed for budbreak. However, although the exponential curve concept is predictive with artificially chilled cuttings placed at a uniform forcing temperature and may be straightforward in colder climates, it does not address how the bud responds to heat interspersed with daily chilling, which in turn reduces the amount of further heat needed. An understanding of how to calculate this heat accumulation may allow development of a more robust model for peach bloom that works across a wide range of environments and experimental treatments.

\section{Literature Cited}

Allan, P., G. Rufus, G.C. Linsley-Noakes, and G.W Matthee. 1995. Winter chill models in a mild subtropical area and effects of constant $6^{\circ} \mathrm{C}$ chilling on peach budbreak. Acta Hort. 409:9-17.

Andersen, T.B. 1991. A model to predict the beginning of pollen season. Grana 30:269-275.

Anderson, J.L., E.A. Richardson, and C.D. Kesner. 1986. Validation of chill unit and flower bud phenology models for 'Montmorency' sour cherry. Acta Hort. 184:71-78.

Cannell, M.G.R. and R.I. Smith. 1983. Thermal time, chill days and prediction of budburst in Picea sitchensis. J. Appl. Ecol. 20:951-963.

Chandler, W.H., M.H. Kimball, G.L. Philp, W.P. Tufts, and G.P. Weldon. 1937. Chilling requirements for opening of buds on deciduous orchard trees and some other plants in California. Univ. Calif. Agr. Expt. Sta. Bull. 611.

Citadin, I., M.C.B. Raseira, F.G. Herter, and J.B. da Silva. 2001. Heat requirement for blooming and leafing in peach. HortScience 36:305-307.

Couvillon, G.A. and A. Erez. 1985a. Effect of level and duration of high temperatures on rest in the peach. J. Amer. Soc. Hort. Sci. 110:579-581.

Couvillon, G.A. and A. Erez. 1985b. Influence of prolonged exposure to chilling temperatures on bud break and heat requirement for bloom of several fruit species. J. Amer. Soc. Hort. Sci. 110:47-50.

Couvillon, G.A. and C.H. Hendershott. 1974. A characterization of the "After-Rest" period of flower buds of two peach cultivars of different chilling requirements. J. Amer. Soc. Hort. Sci. 99:23-26.

del Real-Laborde, J.I., J.L. Anderson, and S.D. Seeley. 1990. An apple tree dormancy model for sub-tropical conditions. Acta Hort. 276:183191.

Dennis,, F.G., Jr. 2003. Problems in standardizing methods for evaluating the chilling requirements for the breaking of dormancy in buds of woody plants. HortScience 38:347-350.

Erez, A., S. Fishman, G.C. Linsley-Noakes, and P. Allan. 1990. The dynamic model for rest completion in peach buds. Acta Hort. 276:165174.

Felker, F.C. and H.A. Robitaille. 1985. Chilling accumulation and rest of sour cherry flower buds. J. Amer. Hort. Sci. 110:227-232.

Fishman, S., A. Erez, and G.A. Couvillon. 1987 The temperature dependence of dormancy breaking in plants: Computer simulation of processes studied under controlled temperatures. J. Theor. Biol. 126:309-321.

Freeman, M.W. and G.C. Martin. 1981. Peach floral bud break and abscisic acid content as affected by mist, light, and temperature treatments during rest. J. Amer. Soc. Hort. Sci. 106: $333-336$.

Gariglio, N., D.E.G. Rossia, M. Mendow, C. Reig, and M. Agusti. 2006. Effect of artificial chilling on the depth of endodormancy and vegetative and flower budbreak of peach and nectarine cultivars using excised shoots. Sci. Hort. 108: 371-377.

Harrington, C.A., P.J. Gould, and J.B. St. Clair. 2010. Modeling the effects of winter environment on dormancy release of Douglas-fir. For. Ecol. Mgt. 259:798-808.
Hauagge, R. and J.N. Cummins. 1991. Seasonal variation in intensity of bud dormancy in apple cultivars and related Malus species. J. Amer. Soc. Hort. Sci. 116:107-115.

Jimenez, S., G.L. Reighard, and D.G. Bielenberg. 2010. Gene expression of DAM5 and DAM6 is suppressed by chilling temperatures and inversely correlated with bud break rate. Plant Mol. Biol. 73:157-167.

Landsberg, J.J. 1974. Apple fruit bud development and growth; Analysis and an empirical model. Ann. Bot. (Lond.) 38:1013-1023.

Linkosalo, T., R. Hakkinen, and H. Hanninen. 2006. Models of the spring phenology of boreal and temperate trees: Is there something missing? Tree Physiol. 26:1165-1172.

Linsley-Noakes, G.C., M. Louw, and P. Allan. 1995. Estimating daily positive Utah chill units from maximum and minimum temperatures. J. S. Afr. Soc. Hort. Sci. 5:19-24.

Mahmood, K., J.G. Carew, P. Hadley, and N.H. Battey. 2000. Chill unit models for the sweet cherry cvs Stella, Sunburst and Summit. J. Hort. Sci. Biotechnol. 75:602-606.

Okie, W.R. 1998. Handbook of peach and nectarine varieties. USDA-ARS Agr. Handbook No. 714.

Pawsut, A., N. Fujishige, K. Yamane, Y. Yamaki, and H. Honjo. 2004. Relationships between chilling and heat requirement for flowering in ornamental peaches. J. Jpn. Soc. Hort. Sci. 73: 519-523.

Reinoso, H., V. Luna, R.P. Pharis, and R. Bottini. 2002. Dormancy in peach (Prunus persica) flower buds. V. Anatomy of bud development in relation to phenological stage. Can. J. Bot. 80:656-663.

Richardson, E.A., J.L. Anderson, and R.H. Campbell. 1986. The Omnidata biophenometer (TA45-P): A chill unit and growing degree hour accumulator. Acta Hort. 184:95-99.

Richardson, E.A., S.D. Seeley, and D.R. Walker. 1974. A method for estimating the completion of rest for 'Redhaven' and 'Elberta' peach trees. HortScience 9:331-332.

Rom, R.C. and E.H. Harrington. 1966. The effect of varying temperature regimes on degree-days to bloom in the Elberta peach. Proc. Amer. Soc. Hort. Sci. 88:239-244.

Scalabrelli, G. and G.A. Couvillon. 1986. The effect of temperature and bud type on rest completion and the $\mathrm{GDH}^{\circ} \mathrm{C}$ requirement for budbreak in 'Redhaven' peach. J. Amer. Soc. Hort. Sci. 111:537-540.

Seeley, S.D. 1996. Modeling climatic regulation of bud dormancy, p. 361-376. In: Lang, G.A. (ed.). Plant dormancy: Physiology, biochemistry and molecular biology. CAB Int., Wallingford, UK.

Seeley, S.D., J.L. Anderson, J.W. Frisby, and M.G. Weeks. 1996. Temperature characteristics of anthesis phenology of deciduous fruit trees. Acta Hort. 416:53-63.

Spencer, S. and G.A. Couvillon. 1975. The relationship of node position to bloom date, fruit size, and endosperm development of the peach, Prunus persica (L.) Batsch cv. Sullivan's Elberta. J. Amer. Soc. Hort. Sci. 100:242-244.

Weinberger, J.H. 1950a. Chilling requirements of peach varieties. Proc. Amer. Soc. Hort. Sci. 56: $122-128$.

Weinberger, J.H. 1950b. Prolonged dormancy of peaches. Proc. Amer. Soc. Hort. Sci. 56:129-133. 